\title{
Transatlantica
}

Revue d'études américaines. American Studies Journal

\section{Les artistes américains et le Louvre}

\section{Catherine Van der Rest}

\section{(2) OpenEdition}

Journals

Édition électronique

URL : http://journals.openedition.org/transatlantica/1161

DOI : 10.4000/transatlantica.1161

ISSN : 1765-2766

Éditeur

AFEA

\section{Référence électronique}

Catherine Van der Rest, «Les artistes américains et le Louvre », Transatlantica [En ligne], 2 | 2006, mis en ligne le 08 janvier 2007, consulté le 29 avril 2021. URL : http://journals.openedition.org/ transatlantica/1161; DOI : https://doi.org/10.4000/transatlantica.1161

Ce document a été généré automatiquement le 29 avril 2021

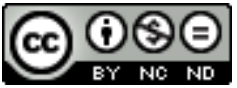

Transatlantica - Revue d'études américaines est mis à disposition selon les termes de la licence Creative Commons Attribution - Pas d'Utilisation Commerciale - Pas de Modification 4.0 International. 


\title{
Les artistes américains et le Louvre
}

\author{
Catherine Van der Rest
}

Exposition présentée à Paris au musée du Louvre, du 14 juin 2006 au 18 septembre 2006, coorganisée avec la Terra Foundation for American Art, et avec le soutien de la Florence Gould Foundation.

Commissaires de l'exposition : Elizabeth Kennedy, conservateur, chargée des collections à la Terra Foundation for American Art et Olivier Meslay, conservateur au musée du Louvre, département des Peintures.

1 L'exposition des peintres américains au Louvre commence et finit avec un constat de manque, dont l'intérêt artistique est emblématique dans le tableau de Samuel F. B. Morse, The Gallery of the Louvre, présenté à part dans le Salon carré, à l'endroit même où l'œuvre fut conçue entre 1831 et 1833 . Ce tableau, hommage du peintre au Louvre, frappe par la valeur didactique dont Samuel F.B. Morse l'avait investi. Le musée, comme ce tableau par transposition, devait servir à éduquer le goût du public, à lui faire connaître et apprécier les œuvres des Grands Maîtres alors tant célébrés en Amérique. Cela peut sans doute expliquer le choix de Samuel Morse de recomposer le tableau, imaginant un accrochage composé de trente-huit chefs d'œuvre des périodes Renaissance et baroque qui figuraient dans d'autres salles, parmi lesquels on peut citer des tableaux de Véronèse, de Claude le Lorrain, de Titien ou encore de Rubens. Mais on peut y voir en filigrane un manque à combler : celui des peintres américains qui, outreAtlantique, n'avaient accès à aucune de ces œuvres et ne pouvaient donc se former artistiquement sans la médiation de copies de Grands Maîtres ou, quand cela leur était possible, par le voyage en Europe dans les académies européennes.

2 Ce constat de manque apparaît aussi dans la salle principale de l'exposition. En effet, la première œuvre exposée, le tableau de Henry Benbridge, Pascal Paoli at the Battle of Ponte Novu (1769), est une œuvre qui n'a jamais figuré dans les collections du Louvre, ayant appartenu à une collection privée avant d'être acquise en 1998 par le musée Pascal Paoli. Or l'intérêt d'un peintre américain pour l'expérience corse d'un régime 
démocratique, même avorté, préfigure des liens étroits que les Américains entretiendront par la suite avec les idées de liberté et de nationalisme inspirées par la France.

3 Ce manque est en quelque sorte confirmé par la conclusion affichée à la sortie de cette salle d'exposition. A la fin du XIXe siècle, le Louvre possédait dans ses collections plus de 120 œuvres d'artistes américains, dont il s'est par la suite "séparé ", au point qu'aujourd'hui il ne reste plus que trois œuvres exposées de façon permanente au Louvre. L'exposition actuelle contient une trentaine d'œuvres réparties en deux temps forts et chronologiques, qui couvrent plus de deux siècles d'histoire de l'art et permettent au public français de découvrir des pans inconnus de l'art américain. Mais, en même temps, cette trentaine d'œuvres majeures représente un échantillon encore restreint de la richesse des liens artistiques entre la France et l'Amérique, bien qu'on puisse y voir l'amorce d'une familiarisation, d'une nouvelle forme de connaissance de l'art américain précédant la deuxième guerre mondiale.

4 La première partie de l'exposition couvre la période allant de l'Indépendance en 1776 jusqu'à la guerre de Sécession en 1861 et a pour objectif d'éclairer l'interaction entre les deux pays, à travers les échanges entre artistes américains et milieux artistiques parisiens. Il est difficile de parler d'influence, lorsqu'on considère que le peintre à qui la plus grande place est accordée, Benjamin West, a été formé en Italie et à Londres, et a surtout eu de l'importance en Angleterre. Il fut pourtant un peintre admiré en France, reconnu (il fut notamment élu membre de l'académie des Beaux-Arts) et exposé au Louvre à plusieurs reprises.

5 Un tout autre aspect de cette interaction entre les deux pays apparaît dans les tableaux de Rembrandt Peale. Ce dernier, membre de la grande famille Peale, qui eut tant d'influence sur la construction des musées en Amérique, voulait à travers la peinture découvrir et faire découvrir aux Américains les personnages célèbres de la France, ce qui n'est pas sans rappeler la fonction didactique de l'œuvre de Samuel F. B. Morse, The Gallery of the Louvre, exposée dans le Salon carré. Les trois portraits exposés, ceux de Jean-Louis David, de Jean-Antoine Houdon et de Dominique Vivant Denon sont emblématiques dans la mesure où on y retrouve trois grands domaines qui fascinaient Rembrandt Peale : la peinture, la sculpture et enfin le musée lui-même, symbolisé ici par son créateur, Vivant Denon. On peut regretter cependant que ne figure pas d'œuvre signalant l'intérêt de Peale pour les arts mécaniques, les sciences ou l'histoire, dont il peignit aussi les figures les plus emblématiques, par exemple George Cuvier ou le naturaliste Geoffroy St-Hilaire.

6 Les deux œuvres de John Vanderlyn sont autant de preuves des interactions entre Américains et Européens : ces tableaux néoclassiques, représentant pour l'un une scène de la mythologie (Ariadne Abandoned on the Island of Naxos, 1809-1814), pour l'autre une scène de l'histoire américaine (The Murder of Jane McCrea, 1804), furent tous deux d'abord vus et célébrés en France avant d'être exposés aux Etats-Unis, où ils furent accueillis par un public d'abord réservé, avant de devenir tous deux emblématiques du néo-classicisme américain.

7 Enfin, le seul tableau de George Catlin présenté dans cette exposition, Indian Ball Game, peint vers 1846, nous rappelle que les peintres américains furent aussi au cœur d'un engouement des Français pour l'Amérique et ses aspects exotiques: lorsqu'il arrive à Paris en 1845, accompagné de douze Indiens, de neuf tonnes de matériel et de 540 peintures rapportées du Missouri, il suscite immédiatement l'intérêt chez Louis- 
Philippe ou encore chez Baudelaire, et est même exposé à titre exceptionnel au Louvre. George Sand et Delacroix viendront tous deux voir cette exposition. Au vu de ce lien très fort avec le Louvre, on peut s'étonner de ne trouver en définitive qu'une seule œuvre de lui dans l'exposition.

8 La deuxième partie de l'exposition correspond aux années suivant la guerre civile, période très faste pour les artistes américains, qui voyagèrent très fréquemment en France pour s'instruire au contact des artistes ou en déambulant dans les galeries du Louvre. Les œuvres sélectionnées cherchent à montrer ce rôle d'académie officieuse pour les peintres américains. On retrouve donc un tableau de James Whistler (At the Piano, 1858-1859), une œuvre de Thomas Eakins (The Swimming Hole, 1885) ou encore une peinture de Mary Cassatt (Mother and Child, 1893), tous trois emblématiques de cette génération de peintres qui migra vers Paris et y obtint ses lettres de noblesse.

Le voyage parmi ces artistes qui ont assidûment fréquenté les milieux parisiens et le Louvre se poursuit à travers le tableau de William James Whittemore, Charles C. Curran (1888-1889), qui illustre une fois de plus ce qu'Elizabeth Kennedy, commissaire de l'exposition, appelle l'« effet Louvre », lorsque, du fait de la fascination qu'il exerce sur les peintres américains, ce dernier se transforme en objet de représentation. La mise en abîme d'un artiste à l'œuvre à l'intérieur du tableau rappelle la peinture de Samuel F. B. Morse et son hommage explicite au Louvre. Mais, contrairement à la représentation minutieuse des chefs d'œuvre du Louvre par Morse, qui traduisait la volonté d'éduquer le goût et les connaissances artistiques des Américains, on n'aperçoit cette fois qu'une partie de sculpture, désormais identifiable par un public de connaisseurs, en France comme aux Etats-Unis.

Les autres artistes représentés dans cette deuxième partie n'ont finalement souvent comme point commun que d'avoir fréquenté le Louvre et d'être citoyen américain. Des artistes du Groupe des Dix tels que Robert Henri au tableau Slaves (1924-1927) de Thomas Hart Benton, de Hopper au Clown with Drum (1842) de Walt Kuhn, l'exposition nous offre un concentré d'histoire de l'art américain, mais le choix des œuvres et le nombre restreint d'artistes et d'œuvres exposées ne permet guère au visiteur de saisir toute l'ampleur de ce mouvement d'interaction, quand on sait que, de 1860 à 1890, plus de 3000 artistes américains ont fréquenté d'une façon ou d'une autre les milieux artistiques français. Le visiteur aura donc l'impression de feuilleter un florilège d'œuvres passionnantes, sans que l'exposition lui permette réellement de saisir toute la complexité et la richesse de ces deux siècles de formation des artistes américains. A l'heure où se dessinent des partenariats et transactions avec les plus grands musées américains, peut-être aurait-on pu rêver d'une exposition plus ambitieuse, mais on ne peut que souligner les grandes possibilités de découverte ou de re-découverte de part et d'autre de l'Atlantique mises en valeur par l'exposition et plus encore par le colloque « De la démocratie en Amérique : Arts, sciences et politique entre la France et les EtatsUnis, 1776-1865 » auquel l'exposition était associée.

11 La liste complète des oeuvres exposées est disponible sur le site du Louvre, www.louvre.fr ou dans le catalogue de l'exposition publié sous la direction de Elizabeth Kennedy et Olivier Meslay. 
INDEX

Thèmes : Trans'Arts 